developing countries, measles has a high morbidity in undernourished children and appears to be one of the events that can trigger acute xerophthalmia. ${ }^{2}$ Moreover, recent work in Africa has indicated that malnourished children frequently acquire herpes simplex virus eye infections after measles. ${ }^{3}$ There is also now experimental work to show that vitamin-A-deficient rabbits, but not control animals, are very susceptible to corneal ulceration from bacterial infection. ${ }^{4}$ Some blinding infections of childhood, which are so common in certain developing countries, must have a nutritional component. The annual incidence of $2: 7$ cases $/ 1000$ of classic corneal xerophthalmia determined by Sommer et al. reflects only blindness attributable to typical severe vitamin-A deficiency and may be only a fraction of the total contribution of malnutrition to blindness.

The prevention of avoidable childhood blindness in developing countries should be based on a multifactorial approach which includes better nutrition (with vitamin A supplementation where appropriate), improved water supplies and hygiene, easily available antibiotics to treat minor eye infections, and systematic measles vaccination.

W.H.O. Collaborating Centre for Prevention

of Blindness and Trachoma,

and Francis I, Proctor Foundation

for Research in Ophthalmology,

University of California,

San Francisco, California 94143 , U.S.A.

Chandler R. Dawson IVAN SCHWAB

\section{CYTOMEGALOVIRUS INFECTION BY NON-PARENTERAL TRANSMISSION}

SIR,-Inge Gurevich and Dr Cunha (Aug. 1, p. 222) report “ . . . the first documented cases of CMV infection caused by non-parenteral transmission of CMV within a nursery". Their claim, if true, has important implications for all hospital personnel who care for sick babies. Unfortunately, they do not present a rigorous argument to substantiate their claim. Although CMV inclusion bodies are one indication of possible CMV infection, no viral cultures were done in this epidemiological study. CMV cultures are routine in any hospital viral diagnostic laboratory, and could have been done on urine samples in suspect cases or on post-mortem tissue.

Most striking, however, is Gurevich and Cunha's failure to acknowledge several reports of the high frequency of $\mathrm{CMV}$ acquisition by infants who have spent a long time in a neonatal intensive care unit (NICU).$^{5-7}$ From 14 to $30 \%$ of all infants older than 3 weeks of age in nurseries become culture-positive for CMV The frequency of CMV serological positivity in these infants may well be higher. CMV acquisition by such infants is greatly dependent upon the number of different blood donors from whom an infant receives blood and the amount of blood an infant receives. When infants born to CMV-negative mothers are transfused with CMV-negative blood, acquisition of the virus can be eliminated. ${ }^{8,9}$ The infants described by Gurevich and Cunha could have acquired their CMV infections through blood transfusions or by passing through an infected cervix during delivery.

Over the past 3 years I have studied the epidemiology of CMV infections in three different NICUs. ${ }^{10}$ Although most cases of CMV

2. Dekkers NWHM. The cornea in measles. The Hague: Dr W. Junk, B V, Publishers,

3. Sanford-Smith JH, whitrle HC. Corneal ulceration following measles in Nigerian children Br J Ophthalmol 1979; 63: 720-24.

4. Carlo JD, Van Horn OL, Hyndiuk RA, Davis SD. Increased susceptrbility to infection in experımental xerophthalmia. Arch Ophthalmol 1981; 99: 1614-17.

5. Spector SA, Schmidt K, Ticknor W, Grossman $M$. Cytomegaloviruria in older infants in intensive care nurseries. 7 Pediatr 1979; 95: 444-46.

6. Ballard RA, Drew WL, Hufnagle KG, Riedel PA. Acquired cytomegalovirus infection in preterm infants. Am $\mathcal{F}$ Dis Child 1979; 133: 482-85.

7. Yeager AS. Transfusion acquired cytomegalovirus infection in newborn infants. $A m \mathcal{F}$ Dis Child 1974; 128: 478-83.

8. Yeager AS, Grumet FC, Hafleigh EB, Arvin AM, Bradley JS, Prober CG. Prevention of transfusion acquired cytomegalovirus infections in newborn infants. $f$ Pediatr 1981; 98: $281-87$.

9. Benson JWT, Bodden SJ, Tobin JO'H. Cytomegalovirus and blood transfusion in neonates. Arch Dis Child 1979, 54: 538-41.

10. Spector SA Molecular analysis of cytomegalovirus infections in hospitalised infants. Pediatr Res 1981, 15: 621. infection were sporadic, our surveillance programme has identified clusters of two to four infants excreting CMV at the same time in one NICU. I agree that these multiple groups of infants with temporally related nosocomial CMV infections suggest that infantinfant transmission of CMV may occur. To help resolve this question, I have made use of restriction endonuclease digestion analyses to compare the DNA fragment migration patterns of the CMV isolates of infants with apparently epidemiologically related infections. So far these analyses indicate that no two infants excreting CMV were infected with the same virus strain. Unfortunately, Gurevich and Cunha do not have the CMV isolates available on which to do restriction enzyme digestion analysis. Confirmation of non-parenteral transmission of CMV in a NICU is therefore lacking.

I share with these workers concern for the possible transmission of CMV from an infected infant to other babies or to nursery personnel. As yet, however, there is no eivdence that such transmission has occurred.

Division of Infectious Disease,

University Hospital,

San Diego, Calıfornia 92103 , U.S.A.;

and Department of Pediatrics,

University of Calıfornia, San Diego

STEPHEN A. SPECTOR

SIR,-Inge Gurevich and Dr Cunha's presentation is consistent with their conclusion that the index infant was the source of nonparenteral transmission of the virus to four other infected infants, but it seems equally consistent with the possibility that the other four infants acquired CMV independently, from other potential reservoirs that were noted elsewhere in the article. One unit of fresh blood was shared by the investigated infants and the donor was seronegative. Was this the only donor used for all the infants during their hospital stays? If not, transfusion of live virus or of latently infected cells with subsequent reactivation has not been ruled out. Inadequate information is supplied to rule out the possibility that infants 3 and 5 acquired their infections at birth from infected maternal secretions at delivery. Was non-pasteurised maternal or donor breast milk fed to any of the infants? If so, evaluation of the donors would be necessary to rule out the possible source of transmission. In the absence of such information, it is not clear to me that CMV transmission was from the index patient or nonparenteral. Restriction endonuclease analysis of the viral DNA in the index case and the other four infected infants would be a stronger tool for assessment of common viral origin and possible routes of transmission. ${ }^{1,2}$

Section of Newborn Services,

Women's Hospital,

and University of Michigan,

Ann Arbor, Michigan 48109, U.S.A.

ROGER G. FAIX

$\star \star$ The Nassau Hospital workers' response follows.-ED.L.

SIR,-Comments on the value of restriction-enzyme analysis for establishing a common source for the CMV encountered in our nursery are well taken. We were unable to pursue that aspect because CMV was not suspected and specimens were not obtained at necropsy of cases 2 and 3. Suspicion of a "cluster" was not aroused until the mother of the twins demonstrated a negative titre while the surviving twin had a raised titre (1:640), and they were not confirmed until the titres from cases 5 were evaluated. By that time, the earlier serum specimens were no longer available.

All infants received multiple transfusions and it is possible, but not very probable, that such a variety of donors would all be CMV carriers. Similarly, some of the infants were fed mother's milk, but again it would be unlikely that a synchronous outbreak would occur from such varied sources.

1. Huang ES, Alford CA, Reynolds DW, et al. Molecular epidemiology of cytomegalovirus: Infections in women and therr infants. N Engl f Med 1980, 303: $958-62$.

2. Spector SA, Spector DH. Use of restriction endonuclease mapping to document nosocomial acquisition of cytomegalovirus (CMV) by monozygotic twins. Pedratr Res 1980; 14: part 2:564 (abstr). 
While we agree that our conclusions are not proven beyond doubt, the temporal proximity of the cases to the index case plus that fact that this is the first such cluster in a nursery, makes this hypothesis the best explanation for what happened. We hope that scientific studies will be directed at either proving or disproving the theory that $C M V$ can be transmitted within nurseries by means other than breast milk and transfusions of blood products.

Infectious Diseases Division,

Nassau Hospital

Long Island, N.Y. 11501 , U.S.A.

Burke A. Cunha INGE GUREVICH

\section{DUAL EFFECT OF SULPHASALAZINE ON COLONIC PROSTAGLANDIN SYNTHETASE}

Sir,-Dr Hoult and Helen Page (Aug. 1, p. 255) describe enhanced release of colonic mucosal prostaglandins (PG) in the presence of submillimolar concentrations of 5-aminosalicylic acid (5-ASA), the colonic metabolite of sulphasalazine (SASP). They suggest that 5-ASA acts as a co-factor for PG biosynthesis and that increased $P G$ production might add to the inhibition of PG degradation by the parent SASP, both mechanisms possibly lowering colonic PG levels during SASP therapy.

We have studied the effect of SASP on PG synthesis by a microsomal fraction of human colonic mucosa using various concentrations of arachidonic acid as substrate. Enzyme preparation, incubation, and radioimmunological determination of PG were as described previously. ${ }^{l}$ As shown in the figure, SASP has a dual effect on human colonic PG synthetase depending on the concentration of arachidonic acid used. Only at high substrate concentrations did ASAP $(0.25 \mathrm{mmol} / \mathrm{l})$ stimulate formation of $\mathrm{PGE}_{2}$ from arachidonic acid: at low substrate concentrations the same concentration of SASP inhibits $\mathrm{PGE}_{2}$ synthesis. At a given concentration of arachidonic acid the effects are dose-dependent for SASP.

In further experiments human colonic mucosa was cut into small pieces, washed, and incubated as whole cell preparation. ${ }^{2}$ The incubation medium was analysed for $\mathrm{PGE}_{2}$ and its 15-keto-13, 14-dihydrometabolite $\left(\mathrm{KH}_{2} \mathrm{PGE}_{2}\right)$. During a $6 \mathrm{~min}$ incubation period SASP $(0 \cdot 25 \mathrm{mmol} / \mathrm{l})$ increased mucosal $\mathrm{PGE}_{2}$ release by $127 \pm 31 \%$ (mean $\pm S E M, n=12$ ). Simultaneously, enhanced formation of the metabolite $\mathrm{KH}_{2} \mathrm{PGE}_{2}$ occurred $(96 \pm 41 \%, \mathrm{n}=7)$, indicating that the increase in $\mathrm{PGE}_{2}$ release was due not to inhibition of PG degradation but to stimulated biosynthesis.

1. Peskar BM. On the synthesis of prostaglandıns by human gastric mucosa and it modification by drugs. Biochtm Biophys Acta 1977; 487: 307-14

2 Peskar BM, Seyberth HW, Peskar BA. Synthesis and metabolism of endogenous prostaglandins by human gastric mucosa. In: Samuelsson B, Ramwell PW, Paolett $R$, eds. Advances in prostaglandin and thromboxane research: Vol VIII. New York: Raven Press, 1980: 1511-14

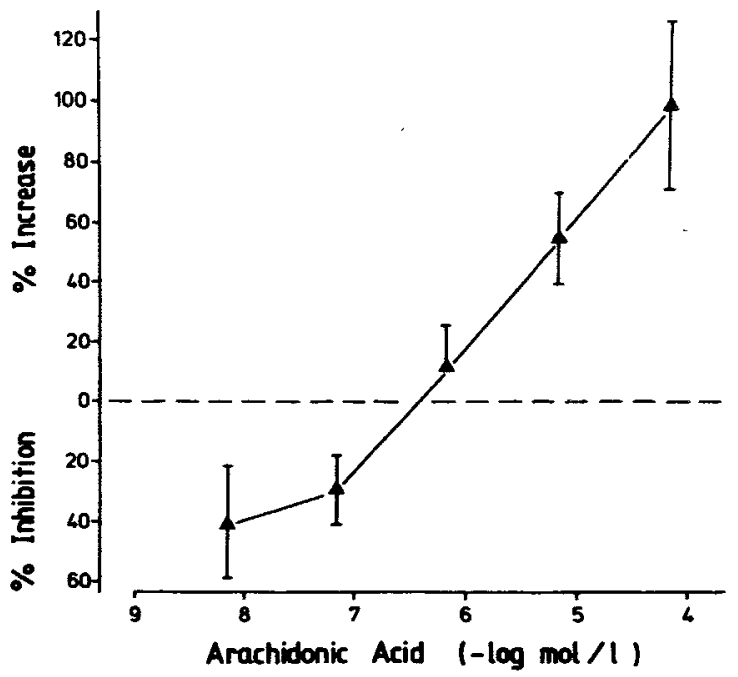

Effect of SASP $(0.25 \mathrm{mmol} / 1)$ on human colonic PG synthetase in presence of various concentrations of arachidonic acid.

Incubations were for $10 \mathrm{~min}$. Values are the mean $\pm S E M$ of 5 experiments.
Our results show that, as for 5-ASA (Hoult and Page), the parent SASP can strongly stimulate endogenous mucosal PG synthesis. However, the effect of SASP on PG synthetase is clearly dependent on the concentration of the substrate arachidonic acid. In intact cells the concentration of free arachidonic acid at the site of cyclooxygenase is controlled by the activity of phospholipase $A_{2}$. This enzyme might, therefore, play a crucial role in determining the effect of SASP on PG synthesis. Stimulation of PG formation observed in short time incubation experiments with whole cell preparations could be due to excess activity of phospholipase $A_{2}$ (induced, for example, by mechanical irritation ${ }^{3}$ ) which in turn leads to high concentrations of free arachidonic acid not necessarily reflecting in situ conditions. As the activity of phospholipase $A_{2}$ may vary in different cells of the gastrointestinal tract and especially with different stages of chronic inflammatory bowel disease we propose that the effect of SASP on PG synthesis in vivo may vary from inhibition to stimulation depending on the local concentration of the substrate fatty acid. Sharon et al. ${ }^{4}$ have found inhibition of PG production by SASP and 5-ASA during $24 \mathrm{~h}$ incubation experiments with human rectal mucosa. Similarly, Smith et al. ${ }^{5}$ reported reduced PG synthesis by human rectal mucosal homogenates in the presence of SASP.

The dual effect of SASP inducing at the same drug concentration stimulation or inhibition of PG biosynthesis depending on the concentration of free arachidonic acid could possibly explain the lack of effect of SASP administration on net mucosal $P G$ production in vivo. ${ }^{6}$ Furthermore, it could correlate to the varying efficacy of SASP therapy in different stages of chronic inflammatory bowel disease. $^{7}$

Department of Gastroenterology,

Medical University Clinic,

D-7800 Freiburg, West Germany

T. SCHLENKER

B. M. PESKAR

\section{SORBITOL, PROSTAGLANDINS, AND ULCERATIVE COLITIS ENEMAS}

SIR,-There has been a lot of interest lately in the role of sulphasalazine in the prostaglandin (PG) metabolism of patients with ulcerative colitis. Enhanced prostaglandin production was observed by measurements in urine, ${ }^{8}$ stool, ${ }^{9}$ and rectal mucosa. ${ }^{10}$ In patients sulphasalazine inhibits prostaglandin production, ${ }^{11}$ and this has been confirmed in vitro. ${ }^{12,13}$ As I have chronic ulcerative colitisand have for some years worked in prostaglandin researchI measured PG levels on samples of my own stool over a 10 day period, according to the method of Gould. ${ }^{9}$ The figure shows the measured PG-like activity, determined on rat stomach strip in a superfused cascade system. ${ }^{14,15}$

3. Flower RJ, Blackwell GJ. The importance of phospholipase- $\mathrm{A}_{2}$ in prostaglandin biosynthesis. Brochem Pharmacol 1976; 25: 285-91

4. Sharon P, Ligumsky $M$, Rachmilewitz D, Zor U. Role of prostaglandins in ulcerative colitıs: Enhanced production during active disease and inhibition by sulphasalazıne. Gastroenterology 1978; 75: 638-40.

5. Smith PR, Dawson DJ, Swan CHJ. Prostaglandin synthetase activity in acute ulcerative colitis: Effect of treatment with sulphasalazıne, codeine phosphate and prednisolone. Gut 1978; 20: 802-05.

6. Rampton DS, Sladen GE. The effect of sulphasalazine withdrawal on rectal mucosal function and prostaglandin $\mathrm{E}_{2}$ release in inactive ulcerative colitis Scand $\mathcal{F}$ Gastroenterol 1981; 16: 157-59.

7. Goldman P, Peppercorn MA Sulfasalazine. N Engl f Med 1975; 293: 20-23.

8. Gould SR, Brash AR, Conolly ME Increased prostaglandin production in ulcerative colitss. Lancet 1977; ii: 98.

9. Gould SR. Assay of prostaglandin-like substances in faeces and their measurement in ulcerative colutis. Prostaglandins 1976; 11: 489-97.

10. Sharon P, Ligumsky M, Rachmilewitz D, Zor U Role of prostaglandins in ulcerative colitts. Enhanced production during active disease and inhibition by sulfasalazıne. Gastroenterology 1978; 75: 638-40.

11. Gould SR, Brash AR, Conolly ME, Lennard-Jones JE. Studies of prostaglandins and sulphasalazine in ulceratıve coltitis. Prostaglandins Med 1981; 6: 165-82

12. Hoult JRS, Moore PK. Sulphasalazine is a potent inhibitor of prostaglandin 15-hydroxydehydrogenase: Possible basis for therapeutic action in ulcerative colitıs. Br F Pharmacol 1978; 64: 6-8

13. Hoult JRS, Moore PK, Ramcharan E. Sulphasalazıne inhibits the pulmonary inactivation of prostaglandins in the rat in vivo. Br 7 Pharmacol 1979; 66: $101 \mathrm{P}-102 \mathrm{P}$.

14. Vane JR. The use of isolated organs for detectung active substances in the circulating blood. Br 7 Pharmacol Chemother 1964; 23: 360-73.

15. Zijlstra FJ, Vincent JE. Contractile characteristics of the rat stomach strip and the rabbit aorta and mesenteric artery. F Pharmacol Meth 1981; 6: 1-4. 